\title{
PROJEÇÃO DAS DESPESAS ASSISTENCIAIS DA SAÚDE SUPLEMENTAR [2018-2030]
}

\section{OBJETIVO}

O objetivo desse estudo é realizar projeções até 2030 do impacto do envelhecimento e do aumento da variação de custos médico-hospitalares ( $\mathrm{VCMH}$ ) sobre a utilização de procedimentos de saúde e sobre as despesas assistenciais de planos de saúde médico-hospitalares. Supondo constantes as taxas de cobertura por faixa etária, considerando o efeito do crescimento da população brasileira e da mudança na composição etária, o número de beneficiários de planos de saúde médico-hospitalares chegará a 51,6 milhões em 2030. Hoje esse número está em 47,4 milhões (dez/18).

\section{$>$ MÉTODO}

Supondo constantes as taxas de cobertura por faixa etária, considerando o efeito do crescimento da população brasileira e da mudança na composição etária dados pelo IBGE, projeta-se o número de beneficiários. Na projeção I a composição de custos é considerada constante e na Projeção II ela varia conforme a média da VCMH/IESS.

\section{RESULTADOS}

A Projeção I (Impacto isolado do crescimento populacional e do envelhecimento da população) aponta que o crescimento da despesa assistencial ocorre concomitantemente com o crescimento da participação dos idosos na despesa no setor de saúde suplementar. Enquanto o número de idosos na faixa etária de 59 anos ou mais crescerá $57,8 \%$, as despesas dessa faixa crescerão $64,9 \%$.

A Projeção II (Impacto do Envelhecimento, do crescimento populacional e da VCMH) mostra que, além do efeito do enveIhecimento, a variação dos custos médico-hospitalares acima da inflação nos próximos anos terá grande impacto sobre as despesas da saúde suplementar. A despesa assistencial total irá mais do que dobrar até 2030 (crescimento de 157,3\%) (Tabela 1).
Tabela 1. Resultados das projeções de gastos e da projeção do número de beneficiários.

\begin{tabular}{|c|c|c|c|}
\hline & $\begin{array}{c}\text { NÚMERO DE } \\
\text { BENEFICIÁRIOS (MILHÕES) }\end{array}$ & $\begin{array}{l}\text { DESPESA ASSISTENCIAL } \\
\text { TOTAL (R\$ BILHÕES) }\end{array}$ & VARIAÇÃO 2017 A 2030 \\
\hline 2017 & 47,3 & $R \$ 149,00$ & - \\
\hline PROJEÇÃO I - 2030 & 51,6 & $R \$ 190,70$ & $27,90 \%$ \\
\hline PROJEÇÃO II - 2030 & 51,6 & $\mathrm{R} \$ 383,50$ & $157,30 \%$ \\
\hline
\end{tabular}

Fonte: Elaboração própria.

Dada a importância relativa das Internações na composição das despesas assistenciais e da alta taxa de utilização pelas faixas etárias mais idosas, esse item de despesa assistencial é o que mais tem impacto sobre os gastos projetados nas duas estimativas.

\section{CONCLUSÃO}

As projeções, principalmente a Projeção II, indicam que o setor de saúde suplementar terá que ter grande atenção para o equilíbrio atuarial das operadoras, dado que o envelhecimento da população é um processo que já está ocorrendo e irá se aprofundar nos próximos anos e o crescimento dos custos médico-hospitalares tem sido continuamente acima da inflação. www.iess.org.br (11) 3706-9747 - contato@iess.org.br
Rua Joaquim Floriano, 1052 - Conj. 42 Itaim Bibi - Paulo/SP - 04534-004 